\title{
The Transcription of Both Classical and Colloquial Arabic
}

When - following a precept of the Prophet's and the orders of Egypt's ruler - Rifā $<\mathrm{a}$ Rāfi< at -Ṭahțāwī (1801-73) undertook to acquaint his co-religionists with useful knowledge amassed even by obdurate unbelievers, he focused his considerable talents on France. In the third chapter of the Introduction of his oft-published and republished Taxlīṣu $l$->Ibrīz fì Talxịși Bārizz, he attempted a quick survey of leading centres of civilisation all over the globe. In so doing, he stumbled on languages which, unlike Arabic, tolerated digraphs that sometimes produce a sound unlike that of either component, and words that crowd strings of consonants into a single syllable, as in his carefully vocalised Was-hin-xi-tūn in al->İtzūniyā. Yet the direction taken made it inevitable that he or his immediate successors would have to familiarise themselves with a widening range of Western writers on kindred subjects, such as David Chisholme. What manual of orthography or morphology would enable any of them to work out how such a name was to be pronounced? Might they have been tempted to spare themselves the guesswork by resorting to transliteration instead of transcription? And would the result have been any less befuddling?

The European pioneers of Arabic studies had more enticing reasons for adopting transliteration.

Enshrined in Scriptures, classical Arabic had been stable for centuries, its syntax and morphology meticulously codified, and - though this was precept rather than reality - it was to be spoken exactly as it was written. And in it had been written all the masterpieces of Arab-Islamic culture that were the main attraction to scholarly Arabists. It was therefore to Standard Arabic, letter for letter, that the European pioneers of Arabic studies bound themselves.

And the transliteralists served their purposes well, not least when they allowed common sense to sideline the principal article of their faith. None so lost sight - or hearing - of the realities of language that he found it necessary to provide a parallel for the silent $>$ alif which literate Arabs add to the masculine plural parts of the conjugation of verbs, or to insert a long $\bar{a}$ in the name of Allāh where no >alif is written into its Arabic form. But the truly committed transliterator, even at the cost of disrupting the metre if he is dealing with verse, will write $f i$ al-šams for 'in the sun' even if he knows that no Arab has ever pronounced it except as $f i \check{s}$-šams.

The great gap in the work of the transliterators is their cold-shouldering of the distinctive features of spoken Arabic, although echoes of it were sometimes committed to writing. Here again the Arab elite must bear some of the responsibility 
for the omission, for they were well aware of the many regional vernaculars, but they looked upon them as corruptions unworthy of serious attention.

But, as I expound in "Arabic Literatures, "Elite" and "Folk": Junctions and Disjunctions' (the first item included in the present book), since at least as early as the thirteenth century the Arab elite has given nods of recognition - though no admission to the literary canon - to some folk verse forms and some folk prose narratives; and since the nineteenth century new trends have appeared in the literature of the Arab elite which have led to the recognition of Arab folk literature at least as a valid subject for academic study. Besides, the use of the colloquial, though still opposed, has gained a foothold at least in the dialogue of plays and of works of fiction of undeniable literary quality.

These developments make it imperative that account be taken of the regional vernaculars of Arabic. Even Arabists who intend to deal mainly with texts in Standard Arabic are likely increasingly to come across illustrative or comparative material drawn from spoken sources, and for these traditional transliteration will not do. At the same time, researchers who wish to confine themselves to Arab folk literature may look upon each regional vernacular as an independent self-subsistent linguistic register, and need only have its phonetic system approximated in Latin characters. I hope to be able to demonstrate that there are instances in which recalling its classical ancestry can be of practical benefit. A new system of transcription that makes accurate differentiation possible must become part of the equipment of any serious Arabist.

I have experimented for years with alternative solutions, and inflicted my fumblings on colleagues and students. I have no illusion that so broad a change from a longestablished pattern will be immediately welcomed, but I have no doubt that in time some scheme along the lines of what I now propose will have to be adopted.

Let me first set forth what I have tried to do and why.

To facilitate standardisation, I have drawn all symbols from the Times New Roman Unicode table.

I find digraphs clumsy, and if used without ligatures confusing, for the constituents of many digraphs also appear as contiguous but separate phonemes, as in adham, ashum, etc.

To retain as much as possible of what is familiar to colleagues, I have built on the foundation laid by Brockelmann, retaining all his symbols except four.

The first two of these exceptions were aimed at cutting down the number of symbols based on ' $g$ ' or ' $h$ ' but differentiated by added diacritics. To serve new needs, I detached from the ' $\mathrm{g}$ ' range the plain ' $\mathrm{g}$ ' which has a direct role to play in distinguishing classical from vernacular usage, for ' $\mathrm{g}$ ' (as in ' $\mathrm{go}$ ') is the way ج, is pronounced in some regional vernaculars (notably in Lower Egypt) whereas ' $j$ ' replaces it in other regions (in Upper Egypt and Syria) and is also widely accepted as the correct classical usage. I therefore found it economical to use these two plain letters as handy symbols for alternative pronunciations of 7 . 
Next, from the ' $h$ ' range of Brockelmann's symbols, I excise his ' $h$ ', which stands for $\dot{\tau}$, borrowing instead ' $x$ ' from the International Phonetic Alphabet; and for its voiced equivalent $\dot{\varepsilon}$ I extend the use of the ' $x$ ' by underlining it, in accordance with an established practice.

My last defection from Brockelmann's ranks is a double one, and it will hit many as all but iconoclastic: I wish to depose a long-established and widely accepted pair of symbols: ' for hamza and ' for $\varepsilon$. My main objection is to their being superscript, for they are not diacritics but letters of the Arabic alphabet that represent phonemes and that may be radical and may be geminated, although they may not have hit the ears of early Arabists as the equals of good honest English consonants. They also have the disadvantage that they may be hard to pick out in print and difficult to distinguish from apostrophes and single quotations marks - how easily can one tell whether ' $a \underline{d} r \bar{a}$ ' is the Arabic for 'virgin' or the verb adrā between single quotation marks? I have searched hard for alternatives correctly aligned, and found none more suitable than ' $<$ ' and ' $>$ ', which have the advantage of being accessible straight from the keyboard.

The question now arises: how spoken Arabic is to be integrated into this system of transcription.

The fact that the vernaculars of Arabic are uninflected affects their syntax and especially their word order considerably, but between the classical and the colloquial vocabularies the gap is not wide. Each region has created coinages and adopted loan words of its own, and gross distortions of pedigreed Arabic words occasionally occur, as when classical wajh, 'face' becomes wišs; but this happens because the abandonment of declension has brought $\mathrm{j}$ and $\mathrm{h}$, which should have been in different syllables, into awkward contiguity. Their kinship, however, is restored in the plural $w u j \bar{u} h$. In the mass, what the regional linguistic variants attest is the liveliness of their common core and the continued prestige of its ancestral form.

Directly relevant to our concern here is a large category of words which differ from the classical only in that one consonant is substituted for another. The change is regular within each regional vernacular: it is not conditional on some specific context and it is always the same consonant that replaces a particular classical one. The words so produced are not temporary formations. They have a life of their own at the colloquial level, and may be thought of as verbal avatars.

Their regularity widens the use that the transcriber can make of them. Thus, ' $q$ ' is widely used for classical $\vec{G}$, and it should continue to do so in the handling of standard texts; but in the Arabic spoken in some regions (such as Lower Egypt and the Levant) $ق$, is uttered as a glottal stop, and in yet other regions (such as Upper Egypt) it becomes a hard g, as in 'go'. In the Arabic script, which has not yet been modified to serve the spoken language, $\overrightarrow{ }$, is still often used to stand for any of the three phonemes it represents, and under the long dominance of transliteration some Western Arabists are tempted to force the same multiple role on q. This one may be forced to do if one is dealing with a folk text available only in the Arabic 
script, with no indication of the region that produced it. Otherwise the temptation must be resisted for it is surely the primary purpose of transcription to produce the closest approximation of the sounds actually uttered. For the regional variants of $\mathrm{q}$ I would therefore choose > and g; but I would also warn the reader that these are departures from standard pronunciation, and this I do by adding a tilde to each of the symbols, producing $\tilde{>}$ and $\tilde{\text { g}}$. Accordingly, the word which in Standard Arabic would be transcribed as waqafa 'he stood' should be wa $\tilde{>} a f$ if it occurs in a Lower Egyptian text, and wagaf in an Upper Egyptian one. And without the symbols that I favour confusion could be twice confused when a folk poet picks a Lower Egyptian gat luh 'she came to him' and an Upper Egyptian gatluh 'killing him' and binds them unequally in a punning yoke!

The benefit of this marker to the reader is that it alerts him to the possibility of searching for the meaning of the word in a standard dictionary, where aids to regional vernaculars are extremely rare. The marker also distinguishes between homonyms, which may be favoured for punning but may be misunderstood.

I have opted to use the tilde (provided it is typographically congruent with the letter to which it is to be attached) to signal departures from Standard Arabic practice. My reason for the choice is that we are as yet familiar with only a few regional vernaculars. As our knowledge expands, we are likely to come across many more local usages to record, and the tilde is the most convenient symbol to use because it is the only available diacritic that may be placed above a letter, below it, or at its midpoint, a bar across the consonant being a suitable alternative if the tilde does not fit in satisfactorily.

Among the avatars, there are several parallels to the transformations that $\mathrm{q}$ undergoes. For example, $\underline{\mathrm{d}}$ and $\underline{\mathrm{t}}$ are hardly ever heard in spoken Arabic. Instead d becomes either d (to be transcribed as d) in some words, as in đakar, 'male'; or (unpredictably) as z (transcribed as z) in others, such as in zākira, 'memory'. Similarly, $\underline{\mathrm{t}}$ becomes $\mathrm{t}$ in some words, such as $t a l t a$, 'three' in some instances, and $\tilde{\mathrm{s}}$ as in $\tilde{s} \bar{a} b i t$, 'firm' in others.

Of the same order, though not so wide in its application, is the fact that when the hamza is the first radical of a word, it often - but not always - turns into a w, which should then be transcribed as $\tilde{\mathrm{w}}$. This differentiates wakkal, which is from the standard root $w-k-l$ and means 'he appointed an agent' from wakkal, which is a variant of $>a k k a l$ from the root $>-\mathrm{k}-1$ and means 'he fed'.

Vowels, especially short ones, do not command much attention in this context as they are chameleon-like in ordinary speech and are never part of the root anyway. Mostly, it is enough if their length as determined by usage is indicated by surmounting them with a macron while leaving the shorter ones unmarked. Only exceptionally - as, for example, in the discussion of the scansion of a passage of verse - one may need to single out vowels shortened where standard syntax requires them to be long; one need only add a tilde to the offending vowel.

Not often invoked, but impossible to ignore, is the distinction between a front 
and a back ' $a$ '. They may then be differentiated by placing a dot beneath the back one. Such 'a's occur whenever the vowel combines with any of the so-called 'dark' or pharyngalised consonants or when it precedes ru or ra, but not ri. All this has long been known to scholars and functions per se as a phonetic phenomenon. It is therefore not necessary to signal it in the transcription. It may also be worth noting mentally that exceptionally in Allāh the ' $\overline{\mathrm{a}}$ ' is pronounced as a back vowel unless the word is preceded by ' $i$ ': compare bi l-lähi and wal-lạhi. More important and not to be overlooked in the transcription are instances in which it is the quality of the ' $a$ ' that determines the meaning of a word, as in the difference between $j \bar{a} r \bar{\imath}$, 'current', and $j \bar{a} r \bar{\imath}$, 'my neighbour'. The phenomenon in fact has a phonemic function in nursery words like $b \bar{a} b a$ and $m \bar{a} m a$ for 'daddy' and 'mummy', in the colloquial word for 'water,' mayya, or in neologisms accepted in formal language, such as the Pope's title: $a l-b \bar{a} b \bar{a}$. In all these instances, it is the entire word that has been coloured, but the vowel is the most distinctively audible, and the dot under it is enough to alert the reader to the phenomenon.

Let us now examine some practices long established in transliteration.

Initial hamzas are almost always omitted by the transliterators. They are also often elided in the vernaculars. One of many distinctions between the different levels of Arabic is that in the colloquial an initial hamza may be and often is elided, whereas in Standard Arabic there are precise norms that determine which may and which may not. A hamzat wașl may therefore be disregarded, but a hamzat qat < ought therefore to be represented by $>$ in transcription, although a long-sustained precedent makes dropping it tolerable where the distinction between standard and colloquial usages does not need to be stressed.

A bone of contention now is the $t \bar{a}>$ marbut $t a h$, the feminine ending in its pausal form, the silent ' $h$ ' signalling that, but for the pause, it would have been a ' $t$ ' carrying a desinential vowel. It has long been transcribed as such, but the third edition of the Encyclopaedia of Islam has decided to drop the ' $h$ '. It is true that since the ' $h$ ' is in fact silent, the ' $a$ ' is sufficient to identify the suffix in most cases, but not if it is appended to a word ending in a long $\bar{a}$. The word fatā, 'young man', could then have no feminine form. To avoid such awkwardness, let the old ' $h$ ' be restored either throughout or at least after long vowels. An incidental effect worth noting is that if the suffix had been declined it would have acquired an additional syllable and the stress (seldom noticed in grammatical discussions of Arabic) would have moved forward; here it does move and remain forward even when the desinence is suppressed.

The same effect occurs in an entirely different construction that also ends with a silent ' $h$ ' after a long vowel. This is when a verb with a $w \bar{a} w$ for a third radical takes a third person masculine singular attached pronoun as its object, and this then goes into its pausal form. The sequence may be $>\operatorname{arj} \bar{u}$ 'I wish' $\rightarrow>\operatorname{arj} \bar{u} h u$ 'I entreat him' $\rightarrow>\operatorname{arju} h$ with the stress moving from the first to the second syllable. Once again, a long vowel followed by an ' $h$ ' at the end of a word signals a shift in 
the stress. Although no rule has been formulated, the arrangement is used even in coining words from foreign sources. Thus, $m \bar{a} y \bar{u}$, with the stress on $m \bar{a}$ is the month of May, and mayūh (Fr. 'maillot') with the stress on yūh is a bathing costume. The formula of a long vowel followed by an $\mathrm{h}$ was accidentally reached, but it seems worth retaining.

My last contribution to this panoply of symbols is a ghost. Arabic does not tolerate contiguous consonants in the same syllable, and in the Standard idiom there are almost always enough desinential vowels to insulate consonants from one another. Not so in the colloquial. Words ending in two consonant are not rare, and if the next begins with yet another - 'a long rope', for example, would be habl tawìl - a speaker would insert a neutral vowel between the two words. For this addition the Arabic script has not yet devised a character, but in an utterance it is unmistakable, and if in verse it would be necessary to the metre. I believe it should appear in a transcription, and to represent it I have considered the Turkish undotted 'i' or the phonetic alphabet's inverted 'e', but I finally opted for I as being neither too elusive nor too intrusive; hence: habl țawìl.

Here, then, is a table of all the symbols - additional to Brockelmann's list or differing from it - needed for the transcription of Arabic. I have, however, taken a liberty with the IPA symbols which mark the pharyngalisation of the 'dark' consonants by superimposing a tilde above each. This is typographically awkward, so I have placed the tilde below each consonant instead.

Colleagues who choose to try out these innovations will find that they give access to new destinations without departing far from the beaten path.

\begin{tabular}{|c|c|c|c|c|}
\hline \multicolumn{2}{|c|}{ Symbol Unicode } & \multirow{2}{*}{$\frac{I P A}{?}$} & \multirow{2}{*}{$\frac{\text { Arabic }}{\&}$} & \multirow{2}{*}{$\frac{\text { Description }}{\text { Glottal stop }}$} \\
\hline$>$ & & & & \\
\hline$\tilde{s}$ & $>+0303$ & ? & ق & $\begin{array}{l}\text { Regional pronunciation of } ق \text {, as in }>a \tilde{>} \bar{u} l \text {, } \\
\text { 'I say' }\end{array}$ \\
\hline$<$ & & $\varsigma$ & $\varepsilon$ & Standard $\varepsilon$ \\
\hline $\mathrm{a}$ & & $a-a$ & fatḥa & Back or front short vowel \\
\hline ạ & 1EA1 & a & fatha & Back 'a', as in Egyptian mayya, 'water' \\
\hline$\overline{\mathrm{a}}$ & 0101 & a:-a: & $>$ alif & Back or front long vowel \\
\hline$\tilde{a}$ & $00 \mathrm{E} 3$ & $\mathrm{a}$ & fatḥa & $\begin{array}{l}\text { Long in Standard Arabic but shortened } \\
\text { colloquially }\end{array}$ \\
\hline $\bar{a}$ & $0101+0323$ & $a:$ & $>$ alif & As in jậr $r \bar{l}$, 'my neighbour' \\
\hline
\end{tabular}




\begin{tabular}{|c|c|c|c|c|}
\hline Symbol & Unicode & $I P A$ & Arabic & Description \\
\hline ḍ & $1 \mathrm{E} 0 \mathrm{D}+0303$ & $\underset{i}{d}$ & 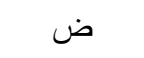 & Pharyngalised ' $d$ ' \\
\hline$\tilde{d}$ & $1 \mathrm{E} 0 \mathrm{D}+0303$ & $\underset{i}{d}$ & ض & $\begin{array}{l}\text { Colloquial substitution of } d \text { for } \mathrm{z} \text { as in } \\
\text { Egyptian } d u h r, \text { 'noon' }\end{array}$ \\
\hline$\underline{\mathrm{d}}$ & $1 \mathrm{E} 0 \mathrm{~F}$ & ð & $\dot{~}$ & Like 'th' in this \\
\hline đ & 0111 & $\mathrm{~d}$ & $\dot{j} \leftarrow$ & $\begin{array}{l}\text { Regional ذ, pronounced 'd' as in đabah, } \\
\text { 'he slaughtered' }\end{array}$ \\
\hline$\overline{\mathrm{e}}$ & 0113 & $\varepsilon:$ & اي & $\begin{array}{l}\text { Colloquial rendering of 'ay' as in } b \bar{e} t \text {, } \\
\text { 'house' }\end{array}$ \\
\hline$\tilde{\mathrm{e}}$ & $1 \mathrm{EBD}$ & $\varepsilon$ & & $\begin{array}{l}\text { Diphthong in Standard Arabic but short } \\
\text { vowel colloquially }\end{array}$ \\
\hline $\mathrm{g}$ & & $\mathrm{g}$ & ج & Cairene $\mathrm{r}$ as in gabal, 'mountain' \\
\hline$\tilde{\mathrm{g}}$ & $\mathrm{g}+0303$ & $\mathrm{~g}$ & 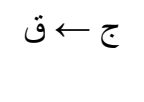 & 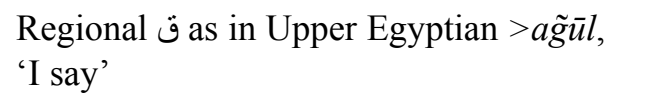 \\
\hline h & $1 \mathrm{E} 25$ & $\hbar$ & $\tau$ & As in hajj, 'pilgrimage' \\
\hline$\overline{1}$ & 012B & i: & ي & Long 'e' as in 'fìh', in it \\
\hline$\tilde{1}$ & $\mathrm{i}+0303$ & $\mathrm{i}$ & & $\begin{array}{l}\text { Shortened form of a long 'e' as in git lak, } \\
\text { 'I came to you' }\end{array}$ \\
\hline I & 026A & ə & & $\begin{array}{l}\text { Neutral vowel added to break a consonantal } \\
\text { cluster, as in Egyptian il-bintı gāt, 'the girl } \\
\text { came' }\end{array}$ \\
\hline $\mathrm{j}$ & & ds & ج & Pronounced 3 in the Levant \\
\hline$\overline{0}$ & $014 \mathrm{C}$ & o: & g & $\begin{array}{l}\text { Colloquial rendering of 'aw', as in } y \bar{o} m \text {, } \\
\text { 'day' }\end{array}$ \\
\hline$\tilde{0}$ & $\mathrm{o}+0303$ & o & g & $\begin{array}{l}\text { Shortened form of long 'o' as in loztē, 'two } \\
\text { almonds' }\end{array}$ \\
\hline q & & q & ق & ق Standard (classical) pronunciation of \\
\hline $\mathrm{s}$ & & $\mathrm{s}$ & س س س & س Standard \\
\hline
\end{tabular}




\begin{tabular}{|c|c|c|c|c|}
\hline Symbol & Unicode & $I P A$ & Arabic & Description \\
\hline$\tilde{\mathbf{s}}$ & $\mathrm{s}+0303$ & $\tilde{\mathrm{s}}$ & س & Colloquial ث as in $\tilde{s} \bar{a} b i t$, 'firm' \\
\hline$\check{\mathrm{s}}$ & 0161 & $\int$ & 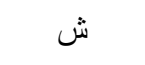 & ش Standard \\
\hline ș & $1 \mathrm{E} 73$ & $\underline{S}$ & ص ص إ & Pharyngalised s \\
\hline $\mathrm{t}$ & & $\mathrm{t}$ & $ت$ & Standard ت \\
\hline $\mathrm{t}$ & 0166 & $\mathrm{t}$ & & $\begin{array}{l}\text { Colloquial rendering of } ث \text { as t: e.g. } t \bar{a} r \text {, } \\
\text { 'revenge' }\end{array}$ \\
\hline$\underline{\mathrm{t}}$ & 0167 & $\theta$ & $ث$ & Standard $\doteq$ \\
\hline $\mathrm{t}$ & $1 \mathrm{E} 6 \mathrm{D}$ & $\underline{\mathrm{t}}$ & b & Pharyngalised $\mathrm{t}$ \\
\hline$\overline{\mathrm{u}}$ & 016B & $\mathrm{u}:$ & و & $\vartheta$ preceded by damma \\
\hline$\tilde{\mathrm{u}}$ & 0169 & $\mathrm{u}$ & g & Shortened form of long ' $u$ ' \\
\hline$\tilde{\mathrm{w}}$ & $\mathrm{w}+0303$ & & $g \leftarrow \varepsilon$ & $\begin{array}{l}\text { Initial hamza changed to w, as in wakkal, } \\
\text { 'he fed' }\end{array}$ \\
\hline $\mathrm{x}$ & & $\mathrm{x}$ & $\dot{\tau}$ & As in >axīr, 'last' \\
\hline$\underline{\mathrm{x}}$ & & r & $\dot{\varepsilon}$ & As in $\underline{x} \bar{e} r$, 'other' \\
\hline$\tilde{z}$ & $\mathrm{z}+0303$ & $\mathrm{z}$ & $j \leftarrow \dot{j}$ & $\begin{array}{l}\text { Colloquial pronunciation of } \dot{j} \text { as in }<u \tilde{z} r \\
\text { 'excuse' }\end{array}$ \\
\hline$z$ & $01 \mathrm{~B} 6$ & $\mathrm{z}$ & $j \leftarrow \dot{j}$ & Alternative to $\dot{ذ}$ as in $<u \tilde{z} r$, 'excuse' \\
\hline $\mathrm{z}$ & $1 \mathrm{E} 93$ & $\underline{z}$ & b & ظ \\
\hline$\tilde{z}$ & $1 \mathrm{E} 93+0303$ & $\underline{z}$ & ظ ط ض ض & $\begin{array}{l}\text { Colloquial substitute for ض, as in Egyptian } \\
\text { ẓa âbiț, 'officer' }\end{array}$ \\
\hline
\end{tabular}


